\title{
MANUSIA DALAM PRAHARA REVOLUSI DIGITAL
}

\section{F. BUdi HARDIMAN*}

\begin{abstract}
Abstrak: Perkembangan yang sangat cepat dalam teknologi komunikasi digital telah mengubah pola-pola adaptasi manusia terhadap lingkungannya. Sudah saatnya filsafat merenungkan ciri manusia di era digital ini bukan sebagai homo sapiens, melainkan sebagai homo digitalis. Homo digitalis, berbeda dari sosok manusia pra-digital, mengalami perubahan tidak hanya dalam cara berkomunikasi, melainkan juga dalam cara merespons dunia dan menangkap kebenaran. Penulis memberi paparan fenomenologis yang kritis tentang kerumitan baru yang timbul akibat digitalisasi masyarakat. Dia berpendirian bahwa dampak revolusi digital bersifat ambivalen, yakni: membuka kebebasan-kebebasan baru dalam komunikasi, tetapi sekaligus juga melepas kebebasan alamiah manusia dalam bentuk brutalitas dalam dunia digital. Sebuah rekomendasi dan kesimpulan diberikan di bagian akhir tulisan ini.
\end{abstract}

Kata-kata kunci: Homo digitalis, kebenaran, digital state of nature, revolusi digital.

Abstract: The fast development of digital communication technology has changed the pattern of human adaptation to their environment. Such shift has prompted philosophy to contemplate on the nature of humans in the time of digital era not as homo sapiens but as homo digitalis. Homo digitalis, being different from the figure of humans in the predigital world, has seen changes not only in the way of communication but also in the way of responding to the world and capturing the truth. The writer will discuss the new complexity arising from the digital society through the lens of critical phenomenology. He asserts that the impact of digital revolution is ambivalent in nature, i.e.: giving access to freedom in communication on one hand, but unleashing human natural freedom that has driven brutalities in the digital world on the other hand. A recommendation is offered and conclusion drawn at the

* F. Budi Hardiman, Fakultas Ilmu Sosial dan Ilmu Politik, Universitas Pelita Harapan, Jl. M.H Thamrin Boulevard 1100, Tangerang, 15811. E-mail: fransiscoergosum@gmail.com. 
end of this paper.

Keywords: Homo digitalis, digital communication, truth, new freedom, digital revolution.

\section{PENDAHULUAN}

Apakah komunikasi digital membuat kita lebih manusiawi dan kurang brutal? Jika ponsel pintar di tangan bagai tongkat sihir dapat menghadirkan pizza, tukang pijat, taksi atau barang dari toko daring dalam beberapa menit, tentu ponsel itu memanusiawikan dan bahkan mendewakan penggunanya, tetapi belum tentu mereka yang dipanggilnya. Literatur-literatur terbaru tentang media sosial dan internet menunjukkan kemungkinan-kemungkinan baru dalam eksplorasi informasi digital yang akan memudahkan kita memantau arus informasi global, tetapi dampak ambivalennya terhadap perilaku manusia kerap luput dari perhatian. ${ }^{1}$ Penerapan komunikasi digital, khususnya dalam politik dan demokrasi, tidak menghasilkan kondisi seperti dibayangkan, sehingga sulit untuk tidak bersikap skeptis terhadapnya.

Di awal modernitas Thomas Hobbes menerbitkan Leviathan (1651), buku yang mencoba menawarkan cara mengatasi kekacauan sosial. Dibayangkannya keadaan sebelum berdirinya negara atau apa yang lalu dikenal dengan istilah state of nature. Di dalam keadaan seperti itu kebebasan setiap orang merupakan ancaman kebebasan setiap orang lainnya, sehingga praktis meniadakan kebebasan itu. "Dalam kondisi itu," demikian Hobbes "Kehidupan bersama manusia tidak hanya menyedihkan, melainkan juga sangat berat." ${ }^{2}$

Hobbes lalu menawarkan sebuah solusi untuk mengakhiri keadaan nestapa itu. Setiap orang menyerahkan hak untuk melakukan segalanya kepada suatu pihak - sebutlah - primus inter pares, asalkan setiap orang lain juga menyerahkan yang sama kepadanya. Pihak itulah yang disebut negara. Hanya dialah yang berhak menggunakan kekerasan kepada

1 Bdk. Luke Sloan et.al. (ed.), The Sage handbook of Social Media Reasearch Methods, Sage, Los Angeles, 2017.

2 Thomas Hobbes, Leviathan, bab 13, Reclam, Stuttgart, 1980, h. 114 
yang lain. Berkat monopoli pemakaian kekerasan ini negara hukum menikmati perdamaian internal. Ancaman hukum telah memaksa warga untuk mengendalikan diri dan memberi respek satu sama lain. Negara memberadabkan manusia.

Dewasa ini, di senjakala modernitas, keadaan telah berubah sangat drastis. Negara hukum tetap berdiri tegak dan kelihatannya kokoh, tetapi perubahan yang sangat cepat sedang menggerogoti Deus mortalis ini dari dalam. Tidak ada darah yang tumpah, tak ada bau mesiu. Yang terjadi adalah suatu pandemi hoaks dengan plintiran kebencian yang memicu konflik horizontal. Demagogi rasis dan orasi kebencian kepada agama lain, seperti selama Pemilu Presiden 2019, dilolongkan kencang-kencang dari revolusi digital yang hanya kelihatannya senyap itu. Dari klik pada gawai dipiculah kekacauan baru, digital state of nature.

\section{SIAPAKAH MANUSIA DI ERA DIGITAL?}

Di dalam perubahan drastis itu, perlulah kita melontarkan pertanyaan di atas. Dalam bukunya Homo Digitalis (2017), Rafael Capurro, seorang filsuf teknologi yang sekarang mengajar di Karlsruhe Jerman, menjelaskan bagaimana perkembangan teknik digital dewasa ini telah mengharuskan filsafat kontemporer untuk memikirkan ulang ontologi, antropologi, dan etika di era digital. ${ }^{3}$ Di sini kita akan memusatkan perhatian lebih pada antropologi. Perubahan besar dalam komunikasi ini tentulah mengubah tidak hanya gaya hidup manusia, melainkan juga pemahaman manusia tentang realitas, tentang dirinya, dan juga tentang baik dan buruk. Komunikasi dan bahasa memang merupakan ciri manusia yang mendasar. Menurut Harari sosialitas homo sapiens berevolusi berkat gosip. "Bergosip sedemikian wajar bagi kita," tulis Harrari, "sehingga tampaknya bahasa kita berevolusi memang untuk alasan ini." ${ }^{4}$ Tidak mengherankan bahwa perubahan dari komunikasi korporeal ke komunikasi digital mengubah ciri mendasar gosip dan kemudian juga bahasa.

3 Rafael Capurro, Homo Digitalis. Beiträge zur Ontologie, Anthropologie und Ethik der gitilaen Technik, Springer VS, Wiesbaden, 2017

4 Juval Noah Harari, Sapiens. Riwayat Singkat Umat Manusia, Kepustakaan Populer Gramedia, Jakarta, cetakan ke-8, 2019, h. 27-28 
Dahulu dalam masyarakat pra-digital Aristoteles menyebut manusia zoon logon echon, mahluk pemakai bahasa. Waktu itu penutur hadir secara ragawi bagi pendengar. Di era digital keduanya telepresent (hadir jarak jauh). Manusia hanyalah sebuah komponen sistem media komunikasi. Ia tampaknya memakai media, tetapi sebenarnya ia sendiri adalah media komunikasi, karena dalam sebuah jejaring anonim komunikasi digital manusia hanyalah penyalur pesan dari internet of things. ${ }^{5}$ Mahluk yang dikendalikan media, berfungsi sebagai media, dan mengadaptasi iklim teknologi digital ini boleh kita sebut homo digitalis. Saya mengutip pertanyaan menarik yang dilontarkan Christian Montag:

Saya sendiri mempersoalkan apakah spesies kita homo sapiens akan berubah secara hakiki lewat keterlibatan terus menerus dengan dunia digital. Apakah homo sapiens di masa depan akan mengalami simbiosis yang lebih kuat lagi dengan teknik digital? Dan apa yang persisnya akan terjadi?...Hasil akhir perkembangan simbiotis itu kemungkinan peralihan dari homo sapiens ke homo digitalis. ${ }^{6}$

Terkesan berlebihan, dugaan tentang peralihan evolusioner dari homo sapiens ke homo digitalis ini beralasan. Kita menyaksikan sekarang ini bagaimana ponsel pintar telah menjadi ekstensi kapasitas pikiran kita. Homo digitalis bukan lagi suatu I think sebagaimana ada sejak Descartes, melainkan suatu I browse. Ia berpikir lewat internet.

Homo digitalis bukan sekadar pengguna gawai. Ia bereksistensi lewat gawai. Eksistensinya ditentukan oleh tindakan digital, yakni: uploading, chatting, posting, dst. Dengannya ia berbagi atau pamer untuk kebutuhan akan pengakuan. Meniru istilah Heidegger, sebagai ganti In-der-Welt-sein, dia adalah In-der-www-sein, yakni berada-dalam-www. Welt (dunia) telah diganti www (Welt-weit-Web). Yang dimaksud “Welt" dalam ontologi Heidegger juga adalah media bagi Dasein untuk memproyeksikan dirinya. Manusia di era digital "berada-dalam" (In-sein) - yaitu betah dengan entitas-entitas digital, seperti: Youtube, Tokopedia, Twitter, Instagram

5 Istilah internet of things mengacu pada interkoneksi digital kehidupan sehari-hari kita dari kulkas, TV, mesin kopi, mobil, rumah sampai kantor dengan internet. Lih. Christian Montag, Homo Digitalis. Smartphones, soziale Netzwerke und das Gehirn, Springer, Wiesbaden, 2018, h. 1

6 Christian Montag, ibid., h. 1. 
sebagai lingkungannya (Umwelt). ${ }^{7}$ Jika www, seperti juga Welt, adalah media bagi Dasein, tidak ada perbedaan mendasar di antara keduanya. Homo digitalis dapat dipikirkan juga sebagai terlempar (geworfen) ke dalam dunia digital. Sejak semula ia memproyeksikan diri melalui media digital. ${ }^{8}$ Anak-anak kita, milenial, yang sepanjang hari tahan di dalam kamar sering dikira putus kontak dengan dunia luar. Perkiraan itu keliru: Mereka terus berkontak dengan www sebagai berada-dalam-www.

Kelahiran homo digitalis ke pentas sejarah dimungkinkan oleh teknologi. Dia semula pengguna gawai, tetapi ketika jejaring komunikasi digital menjadi dunia tersendiri yang beroperasi lepas dari para pencetusnya, ia juga digunakan oleh komunikasi digital untuk tujuantujuan yang tidak di bawah kendalinya. ${ }^{9}$ Di fajar digitalisasi masyarakat, ketika modernisme dan liberalisme seolah mencapai kebebasan individu sebagai target, individu itu sendiri malah menjadi tidak penting, seperti dikatakan Harari: ...manusia akan kehilangan nilai mereka sepenuhnya... manusia masih akan berharga secara kolektif, tetapi akan kehilangan otoritas individual mereka, dan akan diatur oleh algoritma-algoritma eksternal. ${ }^{10}$

Karena itu 'masyarakat' bagi homo digitalis tidak terdiri atas orangorang, karena orang-orang tidak lagi mengendalikan komunikasi, melainkan mengendalikan sekaligus dikendalikannya. Dalam sebuah jejaring komunikasi digital masyarakat terdiri atas pesan-pesan anonim yang terus beredar. Homo digitalis ikut bermain dalam merakit realitas digital. Ia bukan sekadar penonton eristiwa, melainkan juga ikut membuat sejarah dengan memengaruhi komunikasi digital. ${ }^{11}$ Untuk pertama kalinya dalam sejarah, setiap orang biasa menjadi aktor global lewat ruang digital.

7 Lih. Martin Heidegger, Sein und Zeit, paragraf 12, Max Niemeyer, Tübingen, 2001, h. 55.

8 Lih. Rafael Capurro, op cit., h. 35.

9 Ada juga efek-efek negatif pemakaian ponsel. Menurut studi, tiga bulan pemakaian ponsel terus menerus memengaruhi otak anak, seperti: berkurangnya kemampuan untuk mengambil keputusan,mengendalikan emosi, melaksanakan rencana, mengingat, menjadi impulsif. Lih. Christian Montag, op.cit., h. 24.

10 Juval Noah Harari, Homo Deus. Masa Depan Umat Manusia, Pustaka Alvabet, Tangerang Selatan, cetakan ke-3, 2018, h. 399.

11 Bdk. Rafael Capurro, op cit., h. 59. 
Dahulu, di zaman Hobbes dan para modernis, masyarakat itu satu: masyarakat korporeal yang terdiri atas orang-orang. Di era digital manusia hidup juga dengan masyarakat tambahan berupa digital beings, seperti: grup Whatsapp, Twitter, Facebook, Instagram, dst. ${ }^{12}$ Kehadiran terpecah ke dalam dua masyarakat, digital dan korporeal. Kadang sulit menentukan apakah mitra komunikasi kita sedang presen atau telepresen. Tubuhnya memang hadir saat ini di sini, tetapi keterlibatannya saat ini tidak di sini, melainkan di sana, di dalam komunitas virtualnya. Dalam arti tertentu 'schizophrenia' menjadi cara berada digital. Dualisme kehadiran ini bisa saling mengkhianati. Orang tidak bisa sungguh yakin bahwa rapat yang sedang berlangsung tidak sedang disabotase oleh rapat digital lewat ponsel para peserta.

Inilah era, ketika pesan lebih penting daripada pengirimnya. Di dalam masyarakat informasi, seperti dengan jeli dilihat oleh Niklas Luhmann, bukan orang-orang yang berkomunikasi, melainkan 'komunikasi berkomunikasi dengan komunikasi: ${ }^{13}$ Pesan-pesan yang kita kirim direspons dengan pesan-pesan, sehingga pesan-pesan itu sendirilah yang berkomunikasi dengan pesan-pesan lain, sementara orang-orang berfungsi hanya sebagai media untuk meneruskan pesan-pesan itu. Entitas-entitas digital yang tercipta lewat teknologi digital itu, seperti google, wikipedia, youtube, menyerupai intelligentiae separatae dalam filsafat Skolastik. Thomas Aquinas memakai konsep itu untuk menjelaskan apa yang dalam teologi disebut 'malaikat.'14 Komunikasi membentuk sebuah proses mandiri yang dinamis yang bahkan manusia tidak lagi dapat mengontrolnya. Mirip malaikat, yaitu intelligentiae separatae, komunikasi dalam media-media sosial seolah berpikir sendiri lepas dari para partisipan mereka.

Kondisi manusia qua homo digitalis yang 'terperangkap' ke dalam entitas-entitas digital itu kiranya akan disebut oleh Heidegger Gestell atau

12 Keterlibatan kita di dalam grup Whatsapp, Twitter, Facebook, dst. adalah juga cara berada kita secara digital. Pesan-pesan yang saling bertukar di dalamnya harus juga dilihat sebagai keberadaan secara digital. Kita berada secara digital jika bertukar pesan di dalamnya. Sebagaimana keberadaan korporeal, keberadaan digital ditandai dengan tindakan-tindakan, yakni tindakan-tindakan digital.

13 Lih. Kneer/Nassehi, Niklas Luhmanns Theorie sozialer Systeme. Eine Einführung, Wilhelm Fink, München, 1997, h. 67.

14 Bdk. Rafael Capurro, op.cit., h. 13. 
- seperti Capurro menyebutnya - Informationsgestell. ${ }^{15}$ Dulu di era Romantik lahir distingsi antara alam pertama, yaitu alam sebelum diolah, dan alam kedua, yaitu kebudayaan. Informationsgestell di era digital adalah alam ketiga sejauh lahir dari alam kedua. Di era ini perbatasan antara alam, teknologi, dan eksistensi manusia masih ada, tetapi makin subtil, sehingga batas antara originalitas dan artifisialitas makin kabur. ${ }^{16}$ Dunia maya adalah artifisial, tetapi juga sekaligus orisinal, jika dalam praktik telah menjadi lingkungan eksistensial homo digitalis.

\section{KEBEBASAN DAN BRUTALISTAS}

Homo digitalis belum mencapai sosok paripurnanya. Yang sedang terjadi sekarang adalah sebuah peralihan revolusioner yang menghasilkan kebebasan sekaligus brutalitas. Sebagaimana revolusi lain, revolusi digital melepaskan orang dari belenggu tatanan lama dan meraih kebebasan-kebebasan baru dalam komunikasi. Kebebasan digital dinikmati para aktivis media sosial bagai Paris bagi para narapidana yang dilepaskan dari Bastille. Kendali dan pengawasan moral yang membatasi dan mendisiplinkan komunikasi korporeal diabaikan. Sekarang eksibisionisme, narsisme, dan voyerisme justru mendapat panggungnya diruang digital tanpa pengawasan moral dan - meminjam istilahFoucault - tanpa sorot mata psikiatri. Kebebasan baru ini bahkan melambung sampai melepaskan kebebasan alamiah yang selama ini masih dibatasi oleh norma-norma moral dan menghasilkan brutalitas dan kebencian terhadap penganut agama lain. Homo digitalis mendapati dirinya seolah dalam dunia baru tanpa negara, digital state of nature. Dalam keadaan itu adil dan tidak adil tidak dikenali. Setiap orang menjadi hakim dan bahkan tuhan atas yang lain. Kecanggihan gawai membuat pengguna gawai tidak cepat menyadari dirinya bisa menghasilkan brutalitas lewat pesan-pesannya. Homo digitalis menjelma menjadi homo brutalis.

Dalam ruang digital tidak ada urutan zaman, status sosial, hirarki nilai. Setiap pengguna ponsel bisa menjadi penerbit, produser film, wartawan, dan seterusnya tanpa sensor. Yang privat itu publik, yang

15 Lih. ibid, h. 82.

16 Lih. ibid., h. 24. 
publik itu privat. Satu atau banyak sulit diputusan karena tiap pengguna media sosial bisa memiliki ribuan pemirsa. Segala yang privat potensial menjadi politis, karena pengunggahan konten-konten privat yang dibaca publik akan membuatnya politis. Begitu juga setiap saat peristiwa media yang berisi pesan-pesan politis segera menyusupi setiap kamar rahasia ruang privat. Karier pesan dalam ruang digital dapat dicapai hanya sejauh satu klik, asalkan provokatif. Menyendiri dan berkerumun sulit dibedakan karena kerumunan berceloteh dalam gawai yang digenggam seseorang, juga ketika ia sendirian. Sensasi, bukan rasionalisasi, menjadi asas kreativitas. Tahayul menjadi masuk akal, asalkan sensasional.

Sentimentalisasi publik mulai dari bilik yang paling intim. Hal-hal privat, seperti agama, ras, bahkan seks, menjadi stereotip untuk membelah bangsa ke dalam kawan dan lawan. Di era digital ini radikaliame dipupuk dari gawai para peternak massa tanpa demagogi di auditorium. Setiap gawai bisa menjadi ruang indoktrinasi untuk 'kebahlulan suci' yang merusak persatuan. ${ }^{17}$ Kafir mengkafirkan diviralkan lewat keisengan tangan yang gagal memukul balik di suatu hari. Penjelasan untuk hal itu tidak kedaluwarsa: Asap hitam penuh kebencian membumbung dari tungku hati yang dinyalakan terus oleh ketimpangan sosial dan defisit harga diri.

Kebiadaban baru yang berseliweran di ruang digital itu tentu menggema ke dalam demokrasi. Kebencian dan prasangka yang berinkubasi dan terus dipupuk dengan plintiran logika pasca kebenaran menginfeksi organisme sosial nyata. Pentolan tidak perlu lagi menyebar plakat subversif ataupun mengundang massa ke lapangan. Lewat satu klik tindakan digital sambil menyeruput kopi di warteg, mob terbentuk, provokasi diberikan, aksi massa dilancarkan untuk sabotase pemilu, menghentikan ibadah agama lain, atau melakukan persekusi. Betapa mudahnya di era hoaks ini untuk melakukan subversi atas demokrasi

17 Kata 'bahlul' berasal dari kata Arab 'bahlala' yang artinya sesat. Kata itu menggambarkan orang yang kurang berpikir panjang sehingga kerap blunder. Di dalam masyarakat kita makin sering fenomena ini terjadi. Dengan mudahnya orang menuduh orang lain kafir, misalnya, jika ia ikut merayakan hari Valentine, meniup terompet tahun baru, minum Equil, mengucap selamat Natal. Hal lain yang sama sekali konyol adalah, istilah 'om telolet om' diartikan 'saya Yahudi.' 
dan menggerogoti negara hukum dari dalam.

Revolusi digital mengubah lanskap politis kontemporer. Idealideal politis yang konvensional ditantang. Istilah-istilah, seperti sharing economy, e-government, online-learning, dst. akan semakin sering terdengar. Masyarakat semakin terinterkoneksi secara digital; hal itu dapat mempercepat banyak proses yang selama ini terkendala oleh ruang dan waktu. Dahulu kaum Marxis dan sosialis membayangkan masyarakat tanpa kelas, di mana tembok-tembok pemisah antarkelas dibongkar dan hirarki sosial diratakan sehingga tidak ada lagi batas-batas komunikasi antara aku dan kamu, antara kita dan mereka. Tampaknya revolusi digital sedang mendekatkan kita pada utopia seperti itu. Namun utopia semacam itu akan tetap tinggal utopis, selama hoaks mewabah dan kebenaran ditindas oleh berbagai demagogi pasca kebenaran. Negara hukum demokratis sungguh bisa mengalami erosi dari dalam, jika komunikasi dan kebenaran tidak ditegakkan juga dalam komunikasi digital.

\section{NASIB KEBENARAN DI ERA HOAKS}

Frase haus kebenaran kiranya kurang tepat untuk saat ini. Untuk para pengguna gawai saat revolusi digital kata yang lebih tepat adalah haus informasi. Kelimpahan informasi tidak membuat orang tenang. Ada jurang yang makin lebar antara apa yang ia mengerti dan apa yang ia kira harus ia mengerti. Dari kesenjangan inilah muncul suatu perasaan khas yang tidak dimiliki manusia di era lain. Capurro menyebutnya Informationsangst (kecemasan informasi). ${ }^{18}$ Tipe kecemasan ini dapat dijelaskan dengan konsep Neugier (keingintahuan) dalam filsafat Heidegger, yaitu kecenderungan kerumunan untuk tahu sesuatu agar tidak tertinggal dari yang lain. Jadi, perasaan itu bukan dorongan untuk mencari kebenaran, melainkan suatu gairah mimetis primordial untuk ikut tren.

Kebenaran dicari jika kita mengandaikan adanya perbedaan antara ada (being) dan tampak (seeming), antara kenyataan dan bayang-bayang,

antara episteme dan doxa, sebagaimana dilustrasikan oleh Plato dalam 18 Rafael Capurro, op.cit., h. 75. 
perumpamaan goanya di buku Politeia. Dahulu dalam masyarakat pradigital orang berpandangan bahwa media, seperti radio, TV atau koran, adalah bayang-bayang dalam goa Plato itu dan bukan kenyataan. Dewasa ini ketika media menjadi omnipresen, pembedaan itu makin kabur. Setiap pemakai gawai hidup dalam goanya masing-masing dan meyakini kebenarannya masing-masing. Lalu, apa gunanya membedakan antara di dalam dan di luar goa, jika ada begitu banyak goa tempat manusia dapat merasa cukup diri dengan dunia informasinya. Mungkin situasi ini lebih mendekati ‘monad' Leibniz.

Sebelum gawai menengahi komunikasi, kebenaran disampaikan lewat kehadiran korporeal sehingga berada dalam kontrol pengirim pesan. Tidak demikian dengan komunikasi digital. Gawai memediasi kebenaran dengan sistem digital. Sistem itu sendiri bukan media netral karena sirkulasi dan seleksi di dalamnya membangun konstruksi makna tertentu yang berbeda dari intensi pencetusnya. Media ikut menggerus makna yang disampaikan pengirim sehingga tidak lagi diterima oleh penerima sebagaimana dimaksud pengirim. Kebenaran dalam beberapa pengertian klasiknya telah ditantang di era digital ini. Pertama, kebenaran dipahami sebagai korespondensi antara pernyataan dan kenyataan. Kebenaran sebagai korespondensi (corespondence theory of truth) itu mengandaikan fakta yang stabil yang dengannya pernyataan-pernyataan dicocokkan. Di ruang digital pesan-pesan mengalir dan berubah sangat cepat. Fakta pun kehilangan stabilitasnya tergerus oleh komentar-komentar yang tidak berhenti, sehingga berbagai pernyataan itu tidak pernah cocok dengannya.

Kedua, kebenaran juga dipahami sebagai koherensi internal pernyataan-pernyataan yang sesuai dengan kaidah-kaidah logis. Dalam komunikasi digital kebenaran sebagai koherensi itu (coherence theory of truth) juga sulit disampaikan. Di tengah-tengah cepatnya arus kontenkonten digital, entah itu teks, gambar, atau film, sensasi lebih penting daripada koherensi, dan sensasi diperoleh justru lewat inkoherensi sejauh inkoherensi itu dapat memprovokasi sentimen atau emosi. Ketiga, kebenaran juga dipahamani sebagai persetujuan bersama atas 
suatu pernyataan. Kebenaran sebagai konsensus tersebut (consensus theory of truth) mengandaikan diskursus rasional yang konsisten untuk menemukan konsensus, tetapi konsistensi diskursif seperti itu tidak mungkin ketika diskontinuitas menandai aliran isi serial informasi yang fragmentaris. Alih-alih konsensus, disensus menjadi aturan harian dalam komunikasi digital.

Yang tersisa - pengertian keempat tentang kebenaran - adalah kebenaran performatif (performative theory of truth), yakni kebenaran itu dibuat oleh yang memiliki otoritas atau kompetensi dengan membuat pernyataan. Kebenaran performatif inilah yang berlaku dalam komunikasi digital, karena di dalam komunikasi digital kebenaran lebih diciptakan daripada ditemukan. Serial hoaks yang disebarkan terus menerus secara massif akan berubah menjadi kebenaran. Hoaks mendapat status epistemis untuk menuntun praktik. Dalam arti ini 'kebenaran' hoaks berciri performatif, yaitu dibuat real lewat tindakan digital posting, chatting, uploading, dst. Politik yang tidak lagi mengacu pada kebijakan, melainkan menggunakan daya tarik emosional seperti isyu ras, agama, etnisitas, untuk menggaet dukungan disebut post truth politics. Tipe politik ini merupakan contoh pemakaian kebenaran performatif di era digital. Semakin besar dukungan, betapapun konyol isi retorika sang politikus, semakin real kekuasaan yang diraihnya. Di sini kebenaran tidak lebih daripada kehendak - untuk-kebenaran.

Kondisi kebenaran di era digital ini telah diantisipasi oleh Schopenhauer dengan judul bukunya Die Welt als Wille und Vorstellung (dunia sebagai kehendak dan representasi). Dalam komunikasi digital kehendak-kehendak yang beragam direpresentasikan membentuk suatu dunia artifisial pesan-pesan yang terus mengalir atau - dikatakan secara metafisis - suatu digital becoming. Capurro mengatakan bahwa kita sedang hidup dalam era gambaran dunia digital (digitales Weltbild), karena "dunia telah menjadi kehendak dan representasi yang dapat didigitalisasikan."19 Pengguna yang mendapat banyak likes akan memiliki gambaran positif tentang dirinya dan bisa juga ia ketagihan. Tetapi likes

19 Ibid., h. 59. 
yang merangsang otaknya itu suatu kehendak impersonal yang maya. Ke manakah tujuan kehendak metafisis pesan-pesan digital itu? Tidak ke mana-mana, karena dia adalah suatu kehendak yang anonim atau seperti dikatakan filsuf abad ke-19 itu - buta. Kita telah menyebutnya dengan istilah lain, digital state of nature.

\section{MENATA KEMBALI KOMUNIKASI}

Pertanyaan awal sudah dijawab. Pemakaian politis komunikasi digital belum manusiawi. Bahkan jika internet of things menjadi komprehensif dalam hidup kita, yang digital ini bisa menjadi semacam allah yang serba tahu dan serba hadir di manapun. Manusia mendelegasikan pikirannya pada Google karena mesin pencari ini serba tahu. Apakah allah digital itu dapat menertibkan kekacauan akibat revolusi digital dan komunikasi kita lebih manusiawi?

Bayangkan leviathan yang mengawasi dan menghapus semua hoaks. Otoritas penyaring itu dibutuhkan. Pemecahan Hobbesian ini mujarab hanya jika dilaksanakan tanpa monopoli atas kebenaran. Otoritas itu tidak mendominasi semua, melainkan mengawasi batas kebebasan komunikasi. Kebebasan komunikasi menemui batasnya dalam penggunaan kekerasan verbal. Tidak terlalu sulit untuk menyimpulkan bahwa batas inilah yang harus disingkirkan agar kebebasan komunikasi makin besar. Jadi, otoritas yang intoleran terhadap intoleransi dibutuhkan justru untuk menjamin kebebasan komunikasi.

Kebiadaban baru di ruang digital adalah kekacauan komunikasi, maka harus ada manajemen komunikasi juga yang diupayakan secara demokratis. Di era digital media massa, seperti koran, TV, radio, akan tampak kurang demokratis dibandingkan media-media sosial karena media massa konvensional itu kurang interaktif, sedangkan mediamedia sosial sangat interaktif. "Media-media massa itu katolik," seloroh Capurro,"sementara internet menghasilkan suatu reformasi lutheran-mediatis," karena tidak perlu lagi nihil obstat, imprimi potest dan imprimatur untuk pesan-pesan. ${ }^{20}$ Namun perlu diinsyafi bahwa mediamedia massa konvensional masih bermanfaat sebagai rujukan kebenaran 20 Ibid., h. 180-181. 
sebuah berita justru karena adanya proses seleksi dan verifikasi beritaberita. Proses institusional korporeal seperti ini tetap dibutuhkan justru untuk manajemen komunikasi. Tegangan antara kebebasan dan institusionalisasi tetap perlu dipertahankan. Dunia digital tetap harus dianggap sebagai tatanan sekunder, sementara yang primer tetap dunia korporeal.

Untuk memanusiawikan, yakni mengurangi brutalitas, dalam ruang digital saya menyarankan tiga proses penataan komunikasi berikut. Pertama, juridifikasi interaksi digital, yakni: legislasi undang-undang yang makin rinci untuk menata ruang digital. Juridifikasi (Verrechtlichung) adalah proses regulasi berbagai aktivitas kemasyarakatan lewat hukum. Asumsinya, setiap kegiatan baru, seperti misalnya: bisnis daring, adalah wilayah tidak bertuan, suatu state of nature, yang perlu diatur oleh hukum. Komunikasi digital termasuk dalam wilayah baru itu. Juridifikasi dalam pengertian yang diberikan Habermas adalah bagian proses rasionalisasi dunia-kehidupan (Lebenswelt).

Kedua, moralisasi ruang digital, yakni: menyusun dan mensosialisasikan etika komunikasi digital. Juridifikasi saja tidak cukup. Motivasi internal untuk patuh kepada hukum dapat diberikan oleh moralitas. Karena itu juridifikasi perlu disertai dengan sosialisasi etika komunikasi digital yang menghimbau kesadaran moral pengguna gawai untuk melakukan yang baik. Di dalamnya golden rule diterapkan dalam interaksi digital. Pengirim pesan hendaknya memperlakukan penerima pesan seperti ia ingin diperlakukan. Dari Golden Rule ini asas-asas dasar etika, seperti: keadilan, kehendak baik, respek pada person, juga dirinci. Salah satu masalah dalam komunikasi digital adalah bahwa dalam telepresensi keterlibatan tubuh raib, dan akibatnya sulit merasakan situasi, kehilangan trust, memberi komitmen, merasakan tanggungjawab. Etika komunikasi digital perlu merespons kesulitan-kesulitan itu.

Ketiga, solidarisasi jejaring komunitas-komunitas digital untuk melakukan strategi debunking secara komprehensif dan terus menerus terhadap hoaks. Istilah 'debunking' mengacu pada proses pembuktian kepalsuan atau kebohongan topik-topik kontroversial, seperti UFO, 
kegiatan paranormal, dan klaim-klaim agama. Dalam komunikasi digital disinformasi dan hoaks kerap memuat kesesatan logis atau data palsu yang kontroversial dan provokatif dengan tujuan sentimentalisasi publik. Kesesatan logis dan data palsu itu harus diinvestigasi, lalu dibeberkan sebagai tidak benar agar publik dapat mengidentifikasi hoaks sebagai hoaks. Jika perlu, debunking dapat dibeberkan mendahului serangan hoaks, sehingga publik mendapat imunitas terhadap hoaks.

Keempat, penguatan peranan kepemimpinan pluralis di era digital. Komunikasi digital sebagai totalitas juga membutuhkan model, dan model ini bisa diberikan entah oleh para 'demagog' rasis dan fundamentalis atau elite demokratis yang pluralis. Lapisan kepemimpinan yang pluralis ini perlu terus menerus mengorientasikan para pengguna gawai kepada nilai-nilai kemanusiaan dan kebangsaan, sambil menyingkap kesempitan-kesempitan berpikir para demagog media sosial. Tidak ada cara lain untuk menumbuhkan selera publik akan toleransi kecuali lewat kepemimpinan pluralistis.

Akhirnya perlu diingat, revolusi digital tidak menghapus subyek komunikasi, sebagaimana diramalkan para poststrukturalis dan juga tidak membawa manusia kepada penindasan ataupun perbudakan. Memang revolusi ini dapat menyebabkan perpecahan. Namun seperti dikatakan Capurro, komunikasi digital seharusnya membawa kita pada "ketimbalbalikan dan kewajiban-kewajiban satu sama lain." ${ }^{21}$ Homo digitalis adalah mahluk moral yang mencari kebenaran dan keadilan lewat komunikasi digital. Dia mudah terluka, juga oleh kata-kata. Hoaks bersumber dari kerapuhan hati sebagai jalan masuk bagi yang jahat. Alih-alih lewat dusta seharusnya hati diutuhkan lewat bela rasa terhadap yang lain dalam ketulusan. Dalam telepresensi bela rasa menjadi mungkin dengan membayangkan wajah-wajah konkret, bukan sekadar pesan-pesan anonim. Dengan berkurangnya alienasi, komunikasi digital makin berpeluang untuk menjadi manusiawi. Dilihat dari masa depan yang jauh, brutalitas komunikasi digital yang telah dibahas di atas tentu merupakan bentuk primitif homo digitalis yang masih harus memperbaiki

21 Ibid., h. 82. 
diri lewat evolusi peradaban digital.

\section{SIMPULAN}

Tulisan ini merupakan suatu upaya untuk mendiagnosis kondisi manusia di era komunikasi digital. Upaya tersebut menghasilkan beberapa pokok pikiran. Pertama, perkembangan yang sangat pesat dalam komunikasi digital telah menghasilkan kekacauan baru dalam negara hukum demokratis yang dapat disebut digital state of nature. Kedua, revolusi digital telah mendorong filsafat untuk meninjau ulang ontologi, epistemologi, etika dan juga antropologi, sehingga pertanyaan tentang siapa manusia di era digital perlu dijawab. Tulisan ini telah menjawab pertanyaan tersebut dengan memberi beberapa ciri manusia sebagai homo digitalis, yaitu: sebagai komponen sistem komunikasi, bereksistensi lewat gawai, menjadi aktor global dan lokal sekaligus, dan terperangkap dalam kekaburan antara otentisitas dan artifisialitas.

Ketiga, secara politis revolusi digital telah menimbulkan situasi kontradiktoris antara kebebasan dan brutalitas. Komunikasi digital telah memberi kebebasan-bebebasan komunikasi tanpa batas, tetapi kebebasan-kebebasan baru itu de facto dilaksanakan sebagai brutalitas. Tidak hanya terjadi rasionalisasi, melainkan juga sentimentalisasi ruang publik. Keempat, komunikasi digital telah menantang konsep-konsep klasik tentang kebenaran dan menyisakan kebenaran performatif sebagai tipe kebenaran yang berlaku di dalam ruang maya. Kelima, tulisan ini menyarankan tiga proses untuk menata ruang digital, yaitu: lewat juridifikasi, moralisasi, dan solidarisasi. Dengan cara itu digital state of nature diatasi tidak lewat leviathan baru, melainkan secara demokratis.

\section{DAFTAR PUSTAKA}

Capurro, Rafael, Homo Digitalis. Beiträge zur Ontologie, Anthropologie und Ethik der gitilaen Technik, Wiesbaden: Springer VS, 2017.

Harari, Juval Noah, Sapiens. Riwayat Singkat Umat Manusia, Jakarta: Kepustakaan Populer Ramedia, cetakan ke-8, 2019.

Harari, Juval Noah, Homo Deus. Masa Depan Umat Manusia, Tangerang 
Selatan: Pustaka Alvabet, cetakan ke-3, 2018.

Heidegger, Martin, Sein und Zeit, paragraf 12, Tübingen: Max Niemeyer, 2001.

Hobbes, Thomas, Leviathan, bab 13, Reclam, Stuttgart, 1980.

Kneer/Nassehi, Niklas Luhmanns Theorie sozialer Systeme. Eine Einführung, München: Wilhelm Fink, 1997.

Montag, Christian, Homo Digitalis. Smartphones, soziale Netzwerke und das Gehirn, Wiesbaden: Springer, 2018.

Sloan, Luke et.al. (ed.), The Sage handbook of Social Media Reasearch Methods, Los Angeles: Sage, 2017. 